\title{
EVALUASI DESAIN ANTARMUKA APLIKASI BPJSTKU MENGGUNAKAN HEURISTIC EVALUATION
}

\author{
Rini Malfiany ${ }^{1}$, Donny Apdian ${ }^{2}$, Shofa Shofia Hilabi ${ }^{3}$ \\ STMIK Rosma, Manajemen Informatika, Komputerisasi Akuntansi \\ E-mail: rini@dosen.rosma.ac.id \\ Jl. Kertabumi No.62 Karawang 41311
}

\begin{abstract}
ABSTRAK
BPJS Ketenagakerjaan adalah program jaminan sosial yang memberikan fasilitas layanan kepesertaan bagi tenaga kerja ataupun perusahaan (pemberi kerja). Salah satu program BPJS Ketenagakerjaan yang wajib diikuti ialah program Jaminan Hari Tua (JHT).

Untuk mengetahui berapa saldo yang kita dapatkan setiap tahunnya, kita bisa mengetahui nya melalui sebuah aplikasi mobile untuk jaminan Hari Tua (JHT) yaitu aplikasi BPJSTKU. Aplikasi BPJSTKu merupakan aplikasi mobile untuk memberikan pelayanan bagi peserta yang dikhususkan pada tenaga kerja untuk mendapatkan informasi mengenai Saldo Jaminan Hari Tua (JHT) beserta rincian dari Saldo Jaminan Hari Tua (JHT) tahunan. Selain itu aplikasi tersebut menyediakan informasi mengenai data perserta BPJSTKU, simulasi Saldo Jaminan Hari Tua (JHT) juga menyediakan Formulir pengajuan Klaim pengambilan JHT secara online.

Tujuan dibuatnya penelitian ini untuk mengetahui kepuasan atau kekecewaan dari pengguna aplikasi BPJSTKU ini, karena kepuasan pengguna itu merupakan salah satu faktor untuk menentukan tingkat usability sebuah aplikasi.

Untuk menemukan masalah usability pada desain aplikasi BPJSTKU, penelitian ini dibuat dengan menggunakan metode evaluasi Heuristic. Jenis penelitian menggunakan metode kuantitatif karena mengukur kepuasan pengguna dengan Tingkat severity ratings pada masalah usability yang ditentukan dengan skala 0 sampai 4. Lokasi penelitian dilakukan di Karawang dengan sampel staf STMIK Rosma yang menggunakan Aplikasi BPJSTKU.

Dari hasil pengukuran evaluasi heuristic menunjukkan kategori minor usability problem, perbaikan masalah ini diberikan prioritas yang rendah dengan nilai rata-rata 1.88 atau skala 2.

Kata Kunci : Evaluasi Heuristic, Desain Antarmuka, BPJSTKU
\end{abstract}

\begin{abstract}
BPJS Employment is a social security program that provides membership service facilities for workers or companies (employers). One of the BPJS Employment programs that must be followed is the Old Age Security (JHT) program.

To find out how much balance we get each year, we can find out through a mobile application for Old Age Security (JHT), namely the BPJSTKU application. The BPJSTKu application is a mobile application to provide services for participants devoted to the workforce to obtain information about the Old Age Security Balance (JHT) along with details of the annual Old Age Security Balance (JHT). In addition, the application provides information on BPJSTKU participant data, Simulation of Old Age Security Balance (JHT) also provides an online claim form for taking JHT.

The purpose of this research is to find out the satisfaction or disappointment of the users of this BPJSTKU application, because user satisfaction is one of the factors to determine the usability level of an application.

To find usability problems in the BPJSTKU application design, this study was made using the Heuristic evaluation method. This type of research uses quantitative methods because it measures user satisfaction with severity ratings on usability problems which are determined on a scale of 0 to 4. The research location was conducted in Karawang with a sample of STMIK Rosma staff who used the BPJSTKU application.
\end{abstract}


From the results of the heuristic evaluation measurement, it shows the category of minor usability problems, repairing this problem is given a low priority with an average value of 1.88 or a scale of 2.

Keywords: Heuristic Evaluation, Interface Design, BPJSTKU

\section{PENDAHULUAN}

BPJS Ketenagakerjaan adalah program jaminan sosial yang memberikan fasilitas layanan kepesertaan bagi tenaga kerja ataupun perusahaan (pemberi kerja), Program jaminan sosial ini merupakan perlindungan yang bersifat dasar bagi tenaga kerja, yang bertujuan sebagai penjamin alur penerimaan penghasilan bagi tenaga kerja juga keluarganya akibat terjadinya resiko yang tidak diinginkan dengan biaya yang terjangkau oleh perusahaan dan tenaga kerja. (http://www.bpjsketenagakerjaan.go.id)

Salah satu program BPJS Ketenagakerjaan yang wajib diikuti ialah program Jaminan Hari Tua (JHT). Program ini bertujuan untuk menjamin dan memberikan perlindungan kepada tenaga kerja yang sudah tidak bekerja lagi karena sakit batas umur yang menyebabkan tidak bekerja lagi. Dengan adanya program BPJS ini tenaga kerja yang sudah tidak bekerja lagi mendapatkan jaminan dari iuran BPJS ini.

Untuk mengetahui berapa saldo yang kita dapatkan setiap tahunnya, kita bisa mengetahuinya melalui sebuah aplikasi mobile untuk jaminan Hari Tua (JHT) yaitu aplikasi BPJSTKU. Aplikasi BPJSTKu merupakan aplikasi mobile untuk meberikan pelayanan bagi peserta yang dikhususkan pada tenaga kerja untuk mendapatkan informasi mengenai Saldo Jaminan Hari Tua (JHT) beserta rincian dari Saldo Jaminan Hari Tua (JHT) tahunan. Selain itu aplikasi tersebut menyediakan informasi mengenai data perserta BPJSTKU, simulasi Saldo Jaminan Hari Tua (JHT) juga menyediakan Formulir pengajuan Klaim pengambilan JHT secara online.

Versi BPJSTKU Mobile yang diteliti adalah versi 3.1.13. sejak tanggal 12 Februari 2020. Dari hasil penelitian sebelum versi terbaru ini terdapat beberapa komentar yang berisi kekecewaan dan keluhan terkait dengan fitur yang fitur klaim JHT. Rasa kekecewaan yang dialami pengguna ini otomatis menurunkan kepuasan pengguna terhadap aplikasi mobile BPJSTKU. Tujuan dari evaluasi heuristik ini untuk memperbaiki perancangan agar user lebih mudah menggunakan aplikasi BPJSTKU.

Tujuan dari penelitian ini adalah untuk mengevaluasi user interface (UI) dari sebuah produk aplikasi BPJSTKU dengan menggunakan salah satu metode untuk uji usability yaitu 
heuristic evaluation agar aplikasi terlihat bagus dan mudah digunakan dan juga untuk memperbagus user experience sesuai dengan prinsip dari Nelson.

\section{METODE PENELITIAN}

Metode yang digunakan pada penelitian ini menjadi dua bagian yaitu menyebarkan kuisioner tentang objek penelitian yang diujikan dan penghitungan hasil evaluasi heuristik aplikasi BPJSTKU. Kuisioner dilakukan terhadap 30 orang responden pengguna aplikasi BPJSTKU dengan kriteria responden mulai dari jenis kelamin, domisili, informasi kepesertaan, status kepesertaan, usia dan pendidikan. Kuesioner ini berisi pengembangan dari metode evaluasi heuristik yang sudah ada. Pengembangan ini berhubungan dengan dimensi Usability dari evaluasi heuristik dan sub aspek pertanyaan pada kuisioner. Pemilihan sub aspek evaluasi heuristic berdasarkan hasil studi literature yang telah dilakukan sebelumnya, agar didapatkan rancangan kuisioner yang lebih akurat. (J. Nielsen, 1995)

\section{Jenis Penelitian}

Jenis penelitian yang digunakan adalah penelitian penjelasan dengan pendekatan kuantitatif.

\section{Waktu dan Tempat Penelitian}

Penelitian ini dilaksanakan di STMIK Rosma Karawang, waktu penelitian dilaksanakan selama 1 tahun yaitu dari bulan Oktober 2020 sampai dengan bulan September 2021.

\section{Target/Subjek Penelitian}

Populasi yaitu himpunan unit observasi dalam penelitian (Nurdiani, 2014). Populasi dari penelitian ini yaitu pengguna-pengguna yang menggunakan aplikasi BPJSTKU yang ada di Karawang maupun luar Karawang. Hal ini dilakukan, karena peneliti tidak akan mungkin mengetahui berapa jumlah yang pasti dari para pengguna Aplikasi BPJSTKU, karena mempertimbangkan biaya dan waktu penelitian.

Sampel merupakan himpunan unit observasi (bagian dari populasi) yang memberikan keterangan atau data untuk suatu penelitian, terdiri dari nilai atau ukuran peubah - peubah yang bersifat terbatas jumlahnya (Nurdiani, 2014). Tujuan dari pengambilan sampel (sampling) yaitu memperoleh gambaran deskripstif dari karakteristik unit observasi yang termasuk di dalam sampel, dan untuk melakukan generalisasi serta memperkirakan parameter populasi. Hal ini dilakukan karena peneliti tidak dapat melakukan pengamatan secara langsung pada semua unit analisis atau individu yang berada dalam populasi penelitian. Sampel diambil dari pengguna BPJSTKU yang ada di daerah Karawang. 


\section{Prosedur Penelitian}

Tahapan atau proses penelitian yang akan dilakukan dalam penelitian ini dimulai dari studi literatur seperti pada gambar di bawah ini. Dimulai dari studi literature untuk memperoleh data dan referensi yang diperlukan, dilanjutkan dengan membuat sebuah instrument berupa kuesioner, kemudian menyebarkan kuesioner yang telah dibuat. Setelah kuesioner tersebut disebarkan, dilakukan pengumpulan data lalu dilakukan pengolahan serta evaluasi menggunakan evaluasi heuristik sepuluh Nielsen pada Aplikasi BPJSTKU dari data yang telah didapat untuk evaluasi antarmuka dan tahap terakhir mendapatkan kesimpulan dari hasil evaluasi tersebut kemudian merekomendasikan jika memang ada yang darus diperbaiki.

Diagram alir metodologi penelitian diuraikan pada Gambar 1 sebagai berikut:

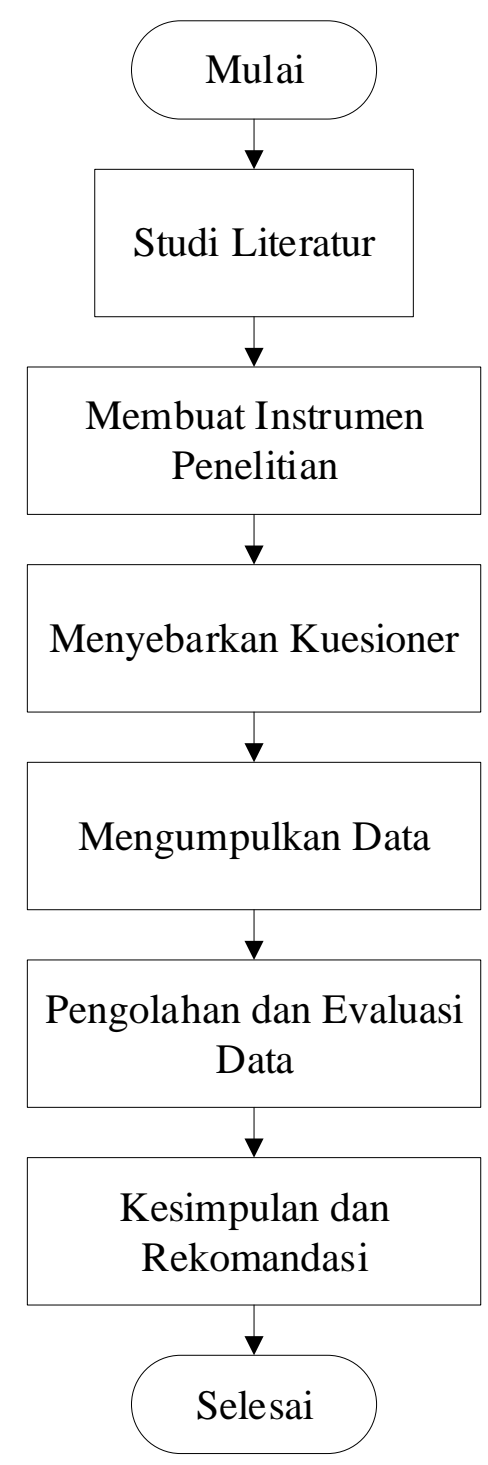


Gambar 1 Diagram alir metodologi penelitian

\section{Data, Instrumen, dan Teknik Pengumpulan Data}

Dalam penelitian ini cara pengumpulan data dilakukan dengan beberapa metode, diantaranya:

1. Kepustakaan (studi literature)

Kepustakaan atau studi libary atau studi literature adalah teknik mengumpulkan data dengan cara mengkaji serta memahami berbagai bahan-bahan bacaan yang erat kaitannya dengan sasaran penelitian seperti literature dari buku, artikel, media internet yang berkaitan dengan masalah yang dihadapi.

2. Wawancara atau interview merupakan salah satu teknik dari pengumpulan data. Pelaksanaannya bisa melalui secara langsung berhadapan dengan yang di wawancarai, tapi juga secara tidak langsung seperti memberikan daftar pertanyaan untuk dijawab pada kesempatan lain. Instrumen dapat berupa pedoman wawancara maupun cheklist.

3. Observasi

Observasi adalah pengamatan dari si peneliti baik secara langsung maupun tidak langsung terhadap objek yang ditelitinya.

4. Kuesioner (Angket)

Teknik kuisioner atau angket adalah suatu pengumpulan data dengan memberikan atau menyebarluaskan daftar pernyataan dengan harapan memberikan respon atas daftar pernyataan tersebut. Dalam penelitian ini angket yang digunakan adalah angket tertutup dimana responden hanya memberikan tanda cheklist $(\sqrt{ })$ pada kolom yang sesuai.

\section{Teknik Analisis Data}

Tabel 1 Aspek Evaluasi Heutiskit dan sub-aspek Evaluasi Heuristik yang digunakan

\begin{tabular}{|c|c|c|}
\hline No & Aspek Evaluasi Heuristik & Sub Aspek Evaluasi Heuristik \\
\hline 1. & $\begin{array}{l}\text { Visibility of System } \\
\text { Status }\end{array}$ & $\begin{array}{l}\text { 1. Untuk setiap halaman memiliki judul yang } \\
\text { menjelaskan isi halaman. } \\
\text { 2. Nama menu dan halaman sudah ada sesuai } \\
\text { dengan isinya. }\end{array}$ \\
\hline
\end{tabular}




\begin{tabular}{|c|c|c|}
\hline & & $\begin{array}{l}\text { 3. Tampilan menu sudah bisa menunjukkan } \\
\text { perbedaan antara yang saat ini dipilih menu dan } \\
\text { tidak dipilih. } \\
\text { 4. Ada respon yang membedakan secara visual } \\
\text { ketika suatu objek diberikan tindakan (dipilih, } \\
\text { tekanan dan lainya.). } \\
\text { 5. Masing-masing simbol / ikon dan desain skema } \\
\text { di setiap halaman sudah konsisten. }\end{array}$ \\
\hline 2. & $\begin{array}{l}\text { Match beetwen system } \\
\text { and the real world }\end{array}$ & $\begin{array}{l}\text { 1. Ikon yang digunakan adalah ikon yang biasa } \\
\text { digunakan secara umum. } \\
\text { 2. Nama menu sudah ditulis logis dan dimengerti } \\
\text { oleh pengguna. } \\
\text { 3. Bentuk/gambar yang digunakan sebagai isyarat } \\
\text { visual sudah sesuai dengan konvensi budaya. } \\
\text { 4. Ada pilihan bahasa untuk mengaktifkan } \\
\text { aplikasi. } \\
\text { 5. Pesan Eror menggunakan bahasa yang } \\
\text { dimengerti. }\end{array}$ \\
\hline 3. & $\begin{array}{l}\text { User Control and } \\
\text { Freedom }\end{array}$ & $\begin{array}{l}\text { 1. Terdapat tombol bantuan ketika sistem tidak } \\
\text { memproses apa pun (misalnya: kesalahan). } \\
\text { 2. Pengguna memiliki fleksibilitas pencarian. } \\
\text { 3. Jika sistem memiliki menu/halaman } \\
\text { berjenjang, pengguna dapat dengan mudah } \\
\text { kembali ke menu/halaman sebelumnya. }\end{array}$ \\
\hline 4. & Consistency and standarts & $\begin{array}{l}\text { 1. Setiap halaman memiliki judul. } \\
\text { 2. Standar penulisan di setiap halaman sudah } \\
\text { konsisten. } \\
\text { 3. Label pada setiap formulir konsisten, jenis } \\
\text { huruf, ukuran, atau paragraf yang bagus. } \\
\text { 4. Tampilan web pada setiap halaman memiliki } \\
\text { kesamaan bentuk dan isi serta konsisten } \\
\text { 5. Setiap halaman tidak hanya menampilkan }\end{array}$ \\
\hline
\end{tabular}




\begin{tabular}{|c|c|c|}
\hline & & $\begin{array}{l}\text { gambar sebagai sumber informasi sehingga } \\
\text { dapat memenuhi aksesibilitas standar untuk } \\
\text { pengguna penyandang disabilitas khusus (buta } \\
\text { atau low vision) }\end{array}$ \\
\hline 5. & Error Prevention & $\begin{array}{l}\text { 1. Teks pada instruksi jelas dan tidak } \\
\text { menyebabkan arti ganda (ambigu). } \\
\text { 2. Informasi telah dikelompokkan dengan baik. } \\
\text { 3. Terdapat navigasi panduan untuk pengguna } \\
\text { disetiap halaman. }\end{array}$ \\
\hline 6. & $\begin{array}{l}\text { Recognition rather than } \\
\text { recall }\end{array}$ & $\begin{array}{l}\text { 1. Terdapat pesan error yang bersifat teknis (mis. } \\
\text { tampilkan kode sumber) ketika gagal } \\
\text { mengakses sebuah halaman. } \\
\text { 2. Ada peringatan ketika pengguna membuat } \\
\text { kesalahan dalam pengisian. }\end{array}$ \\
\hline 7. & $\begin{array}{l}\text { Flexibility and efficiency } \\
\text { of use }\end{array}$ & $\begin{array}{l}\text { 1. Menu dan informasi ditampilkan dengan baik. } \\
\text { 2. Pengelompokan menu dan informasi dapat } \\
\text { mudah diingat. } \\
\text { 3. Terdapat navigasi yang bisa membantu di } \\
\text { setiap halaman. }\end{array}$ \\
\hline 8. & $\begin{array}{l}\text { Aesthetic and minimalist } \\
\text { design }\end{array}$ & $\begin{array}{l}\text { 1. Ada pilihan bahasa yang bisa mengakomodasi } \\
\text { pengguna di luar negeri } \\
\text { 2. Pencarian menu mudah dikenali dan digunakan } \\
\text { khusus untuk pemula } \\
\text { 3. Tata letak menu akrab dan mudah dapat } \\
\text { diakses oleh pengguna } \\
\text { 4. Terdapat pilihan jika ukuran font tampilan } \\
\text { huruf dianggap kecil oleh pengguna } \\
\text { 5. Tidak membuat pilihan warna sebagai kode } \\
\text { dalam tindakan }\end{array}$ \\
\hline 9. & $\begin{array}{l}\text { Help users recognize, } \\
\text { diagnose, and recover } \\
\text { from errors }\end{array}$ & $\begin{array}{l}\text { 1. Informasi sudah ditampilkan di setiap halaman } \\
\text { memungkinkan pengguna untuk dapat } \\
\text { mengambil keputusan. }\end{array}$ \\
\hline
\end{tabular}




\begin{tabular}{l|l}
\hline 2. Ada pilihan font (jenis, ukuran) di situs web \\
yang membuat pengguna betah. \\
3. Struktur setiap halaman sudah konsisten dan \\
seragam \\
4. Judul setiap halaman jelas dan informatif \\
5. Ada atribut, gambar, atau informasi itu tidak \\
relevan \\
1. Terdapat peta situs yang memudahkan \\
pengguna melihat menu selengkapnya \\
2. Terdapat menu bantuan yang dapat membantu \\
pengguna lebih baik \\
3. Terdapat fasilitas contact /korespondensi dari \\
situs web pemilik
\end{tabular}

Sumber: (J. Nielsen, 1995)

Untuk skala penilaian dari tingkat keparahan masalah usability dari evaluasi heuristiknya, berupa peringat dari 0 sampai 4 (tingkat severity ratings). (J. Nielsen, 1995) 0 = Tidak menjadi masalah.

1 = Kategori cosmetic problem, masalah tidak perlu diperbaiki, kecuali tersedia waktu tambahan untuk project.

2 = Kategori minor usability problem, perbaikan masalah ini diberikan prioritas yang rendah.

3 = Kategori major usability problem, perbaikan masalah ini diberikan prioritas yang tinggi.

4 = Kategori usability catastrophe, masalah ini harus diperbaiki sebelum produk direlease.

Hasil kuisioner menggunakan severity rating yang dihitung didapat dari rerata masingmasing atribut pada setiap prinsip uji usability atau aspek evaluasi heuristic. Setiap aspek uji usability pada evaluasi heuristik memiliki sub aspek usability atau sub aspek evaluasi heuristic yang merupakan poin pengembangan yang sesuai dengan aspek evaluasi usability.

Pada perhitungan evaluasi heuristic menggunakan persamaan (1):

$$
\sum H x=0 * x+1 * x+2 * x+3 * x+4 * x+5 * x .
$$

Dengan, 
$\sum H x=$ jumlah skor rating dari sub-aspek evaluasi heuristik pada setiap aspek evaluasi heuristik (H1, H2, H3, H4, H5, H6, H7, H8, H9, H10)

$x=$ poin usability/point evaluasi heuristik

Berikutnya untuk menghasilkan nilai severity rating dari tiap aspek evaluasi heuristik menggunakan persamaan (2):

$$
S v=\sum \frac{H x}{n}
$$

Dengan,

$S v=$ hasil severity rating dalam satu aspek evaluasi heuristik

$n=$ banyaknya sub-aspek evaluasi heuristik dalam setiap aspek evaluasi heuristik (Farida,

L.Dwi, 2016)

\section{HASIL PENELITIAN DAN PEMBAHASAN}

Hasil Penelitian

Tampilan aplikasi BPJSTKU yang akan dievaluasi menggunakan evaluasi heuristik seperti pada gambar di bawah ini:

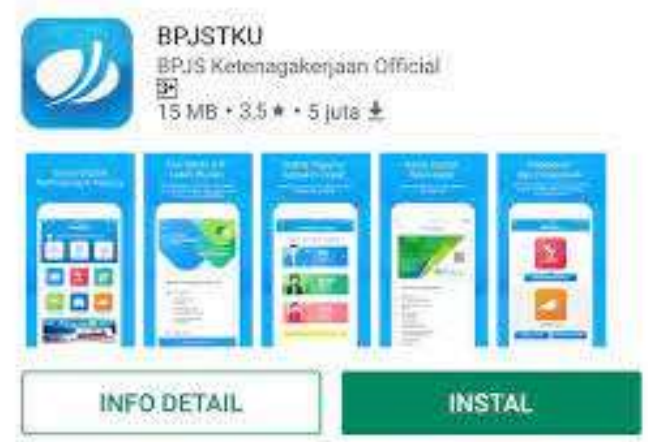

Gambar 2 Menu Download aplikasi BPJSTKU di ponsel.

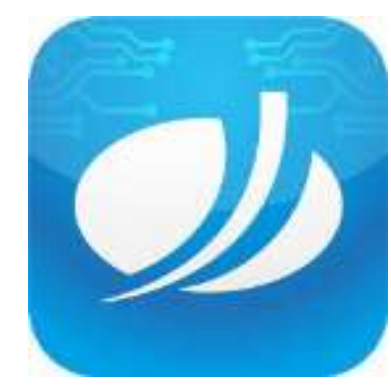

Gambar 3 Simbol Aplikasi BPJSTKU 
Rini Malfiany, Donny Apdian, Shofa Shofia Hilabi Vol 6 No 1

ISSN : 2541-6995

E ISSN : 2580-5517

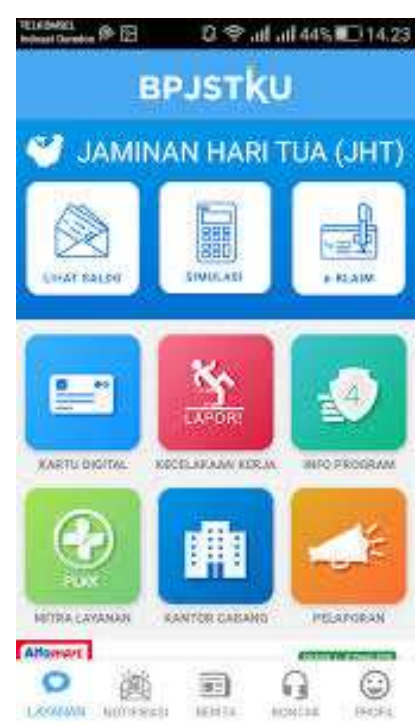

Gambar 4 Tampilan Informasi yang ada pada BPJSTKU

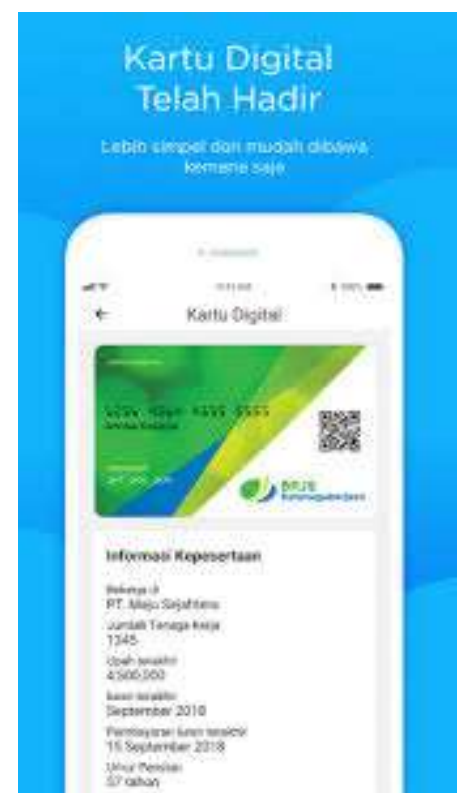

Gambar 5 Tampilan Informasi Kepesertaan BPJS Ketenagakerjaan di BPJSTKU

\section{Data Diri}

Jenis Kelamin

30 jawaban

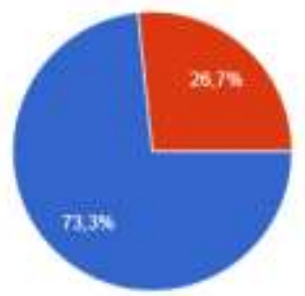

- Lachlan

- Ferenguar 


\section{Gambar 6 Hasil Responden Berdasarkan Jenis Kelamin}

\section{Keterangan :}

Jumlah responden laki-laki lebih banyak yaitu ada 22 orang dengan persentasi 73,3\% sedangkan perempuan ada 8 orang dengan persentasi $26,7 \%$

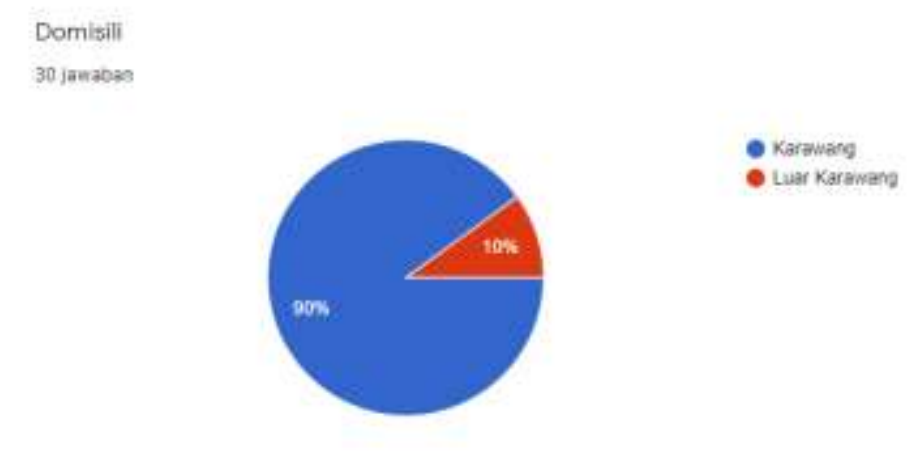

Gambar 7 Hasil Responden Berdasarkan Domisili

Keterangan :

Untuk domisili responden lebih banyak yang tinggal di Karawang dibandingkan dengan luar Karawang. Domisili di Karawang berjumlah 27 orang dengan persentasi 90\% sedangkan luar Karawang ada 3 orang dengan persentasi $10 \%$

Informasi Kepesertaan

30 jawaban

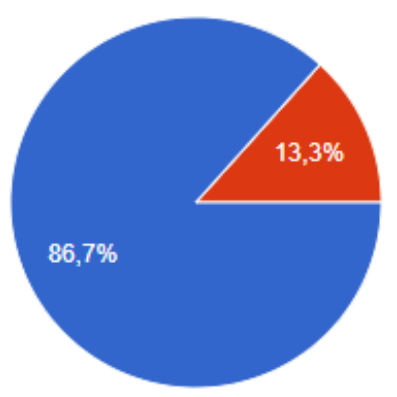

Penerima Upah (Karyawan)

Bukan Penerima Upah (Wirausaha, Freelancer, Pekerja Paruh Waktu)

Jasa Kontruksi (Pekerja Jasa Kontruksi)

Pekerja Migran Indoensia

Gambar 8 Hasil Responden Berdasarkan Informasi Kepesertaan

Keterangan :

Responden dilihat dari informasi Kepesertaan lebih banyak lebih banyak yang tinggal di Karawang dibandingkan dengan luar Karawang. Domisili di Karawang berjumlah 27 orang dengan persentasi $90 \%$ sedangkan luar Karawang ada 3 orang dengan persentasi $10 \%$ 


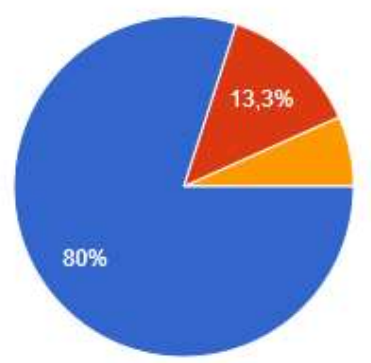

Masin Aktif

Peserta lanjutan yang pernah terdaftar

Tidak Aktif

\section{Gambar 9 Hasil Responden Berdasarkan Status Kepesertaan}

\section{Keterangan :}

Status Kepesertaan responden terdiri dari tiga status, masih aktif, peserta lanjutan yang pernah terdaftar dan tidak aktif. Dari 30 responden, yang mengisi kuisioner ini adalah peserta bpjs ketegakerjaan yang masih aktif sebanyak 24 orang dengan persentase $80 \%$, peserta lanjutan yang pernah terdaftar pada BPJS ketenagakerjaan sebelumnya ada 4 orang, 13,3\% dan terakhir responden yang sudah tidak aktif ada 2 orang dengan persentase 2,67\%.
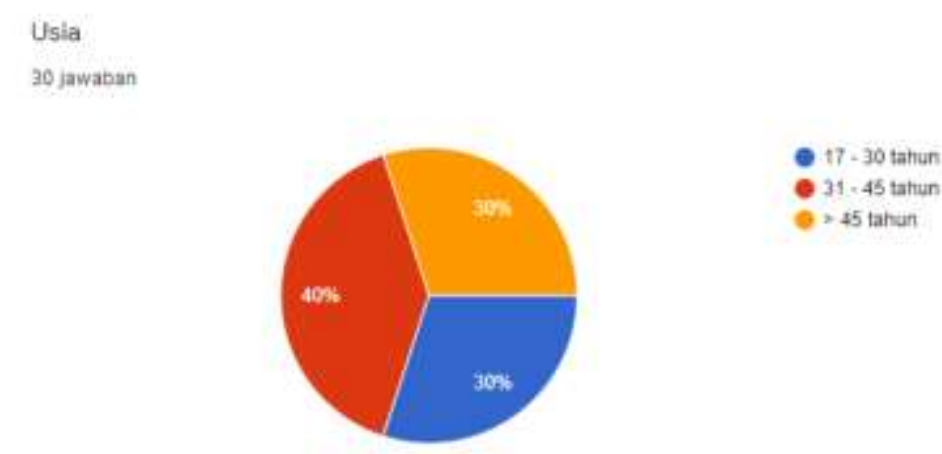

Gambar 40 Hasil Responden Berdasarkan Usia

\section{Keterangan :}

Dalam hal usia, status Kepesertaan responden dibagi menjadi 3 bagian, antara usia 17 - 30 tahun, 31 - 45 tahun dan lebih dari 45 tahun. Responden dengan usia 17 - 30 tahun dari 45 tahun sama banyak yaitu 9 orang dengan persentase $30 \%$ semua, dan yang paling banyak responden berusia antara 31 - 45 tahun sebanyak 12 orang dengan persentase $40 \%$. 


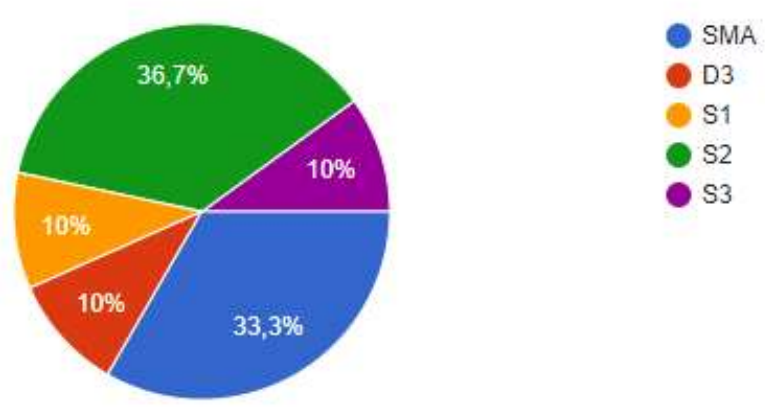

Gambar 41 Hasil Responden Berdasarkan Pendidikan

Keterangan :

Responden dengan tingkat pendidikan di mulai dari SMA sampai dengan S3. Pendidikan dengan S2 yang paling banyak dalam responden ini sebanyak 11 orang dengan persentase $36,7 \%$, berikutnya responden dengan pendidikan SMA sebanyak 10 orang dengan persentase 33,3\%, pendidikan SMA, D3 dan S1 masing-masing sama sebanyak 3 orang dengan persentase $10 \%$.

\section{Pemabahasan}

Setelah penyebaran kuisioner mengenai aplikasi BPJSTKU ini dengan menentukan aspek dan sub-aspek evaluasi heuristik maka dilakukan penghitungan nilai hasil evaluasi heuristik dengan rekapitulasi data rating sebagai berikut:

Tabel 2 Contoh Perhitungan Aspek Evaluasi Heuristik

\begin{tabular}{|c|c|c|c|c|c|c|c|c|}
\hline \multirow[t]{2}{*}{$\begin{array}{c}\text { Aspek Evaluasi } \\
\text { Heuristik }\end{array}$} & \multirow{2}{*}{$\begin{array}{c}\text { Sub Aspek } \\
\text { Evaluasi } \\
\text { Heuristik }\end{array}$} & \multicolumn{5}{|c|}{$\begin{array}{c}\text { Severity Rating } \\
(S R)\end{array}$} & \multirow[t]{2}{*}{$\begin{array}{c}\text { Jumlah } \\
\text { SR }\end{array}$} & \multirow[t]{2}{*}{ Nilai $S K$} \\
\hline & & 0 & 1 & 2 & 3 & 4 & & \\
\hline (A) & (B) & $(\mathrm{C})$ & (D) & (E) & $(\mathrm{F})$ & $(\mathrm{G})$ & $(\mathrm{H})$ & (I) \\
\hline \multirow{7}{*}{$\begin{array}{l}\text { Visibility of } \\
\text { System Status }\end{array}$} & 1 & 8 & 4 & 4 & 8 & 6 & 60 & 2,00 \\
\hline & 2 & 11 & 4 & 4 & 5 & 6 & 51 & 1,70 \\
\hline & 3 & 3 & 7 & 6 & 8 & 6 & 67 & 2,23 \\
\hline & 4 & 3 & 7 & 6 & 6 & 8 & 69 & 2,30 \\
\hline & 5 & 5 & 6 & 7 & 6 & 6 & 62 & 2,07 \\
\hline & & 30 & 28 & 27 & 33 & 32 & & 10,30 \\
\hline & & 0 & 28 & 54 & 99 & 128 & & 2,06 \\
\hline
\end{tabular}

Keterangan : SR (Severety Rating)

Contoh perhitungan Tabel 2. Daftar nilai severety rating pada kolom C,D,E,F,G adalah nilai dari evaluasi heuristik yang dilakukan dengan survei. Kolom I merupakan kolom yang berisi 
jumlah severety rating yang diperoleh dari penjumlahan nilai severety rating. Sesuai persamaan 1 bahwa

$\mathrm{H}=(0 * \mathrm{C} 1)+(1 * \mathrm{D} 1)+(2 * \mathrm{E} 1)+(3 * \mathrm{~F} 1)+(4 * \mathrm{G} 1)$

$\mathrm{H}=(0 * 8)+(1 * 4)+(2 * 4)+(3 * 8)+(4 * 6)$

Selanjutnya kolom I merupakan nilai severety rating yang didapatkan yaitu $\mathrm{I}=\mathrm{H} / 30$ dan Nilai akhir severety rating diperoleh dari $\mathrm{SR}=\mathrm{I} / 5$

Berdasarkan hasil perhitungan di atas, nilai severety rating untuk Evaluasi Heuristik Visibility of System Status berada diangka 2,06 atau dibulatkan menjadi 2, dengan kategori minor usability problem, artinya perbaikan masalah ini diberikan prioritas yang rendah. Permasalahan Terendah pada Visibility of System Status adalah nama menu dan halaman sudah ada sesuai dengan isinya. Sedangkan permasalahan tertinggi pada Visibility of System Status mengenai respon yang membedakan secara visual ketika suatu objek diberikan tindakan (dipilih, tekanan dan lainya).

Berdasarkan perhitungan dari sepuluh aspek evaluasi heuristik, maka hasil uji semua ditampilkan pada tabel berikut ini.

Tabel 3 Rekapitulasi Nilai Severety Rating Aplikasi BPJSTKU

\begin{tabular}{|l|c|c|}
\hline \multicolumn{1}{|c|}{ Aspek Evaluasi Heuristik } & $\begin{array}{c}\text { Nilai Rata-rata } \\
\text { Severety } \\
\text { Rating }\end{array}$ & $\begin{array}{c}\text { Nilai } \\
\text { Pembulatan } \\
\text { Skala 0-4 }\end{array}$ \\
\hline Visibility of System Status & 2,06 & 2 \\
\hline Match beetwen system and the real world & 1,93 & 2 \\
\hline User Control and Freedom & 2,20 & 2 \\
\hline Consistency and standarts & 1,64 & 2 \\
\hline Error Prevention & 1,74 & 2 \\
\hline Recognition rather than recall & 1,90 & 2 \\
\hline Flexibility and efficiency of use & 1,71 & 2 \\
\hline Aesthetic and minimalist design & 1,92 & 2 \\
\hline Help users recognize, diagnose, and recover from errors & 1,75 & 2 \\
\hline Help and documentation & 1,91 & 2 \\
\hline Nilai Rata-rata Severety Rating & 1,88 & 2 \\
\hline
\end{tabular}


Berdasarkan hasil uji pada table 13 di atas dengan menggunakan evaluasi heuristic, nilai dari severety rating menunjukkan seberapa besar masalah usability desain antamuka pada aplikasi BPJSTKU. Pada tabel di atas desain antarmuka BPJSTKU memiliki masalah usability dengan kategori minor usability problem, perbaikan masalah ini diberikan prioritas yang rendah dengan nilai rata-rata 1.88 atau skala 2.

\section{KESIMPULAN DAN IMPLIKASI}

Kesimpulan Setelah dilakukan uji usability dengan evaluasi heuristic pada aplikasi BPJSTKU maka didapatkan kesimpulan sebagai berikut :

1. Berdasarkan uji usability dengan evaluasi heuristik, masalah usability yang paling besar terdapat pada aspek User control and freedom dengan sub aspek tombol bantuan ketika sistem tidak memproses apa pun (misalnya: kesalahan) dengan nilai severety rating 2,20 sedangkan nilai terendah terdapat pada aspek Consistency and standarts dengan sub aspek Setiap halaman memiliki judul dengan nilai severety rating 1,64.

2. Nilai rata-rata keseluruhan dari semua aspek evaluasi heuristik ini bernilai 1,88 atau skala 2 yang berarti kategori minor usability problem, perbaikan masalah ini diberikan prioritas yang rendah.

Implikasi

Dengan melihat hasil penelitian ini, maka diberikan saran untuk penelitian berikutnya, antara lain :

1. Hasil pengujian yang telah dilakukan dalam penelitian ini digunakan sebagai saran untuk menjadikan aplikasi BPJSTKU lebih baik lagi untuk pengguna agar lebih dimengerti lagi penggunaannya

2. Untuk peneliti berikutnya, dapat mengembangkan Kembali evaluasi usability dengan metode yang lain untuk lebih mendukung hasil pengujian.

\section{DAFTAR PUSTAKA}

Fahry Nur Muhammad, Suprapto, Admaja Dwi Herlambang. (2018) Evaluasi Desain Antarmuka Aplikasi Mobile BPJS Ketenagakerjaan Menggunakan Heuristic Evaluation. Jurnal Pengembangan Teknologi Informasi dan Ilmu Komputer e-ISSN: 2548-964X Vol. 2, No. 1, Januari 2018, hlm. 433-440 http://j-ptiik.ub.ac.id 
Farida, L.Dwi, (2016) Pengukuran User Experience Dengan Pendekatan Usability (Studi Kasus: Website Pariwisata Di Asia Tenggara), SEMNASTEKNOMEDIA.

J. Nielsen, “Ten Usability Heuristics," Januari, 1995. [Online]. Available: http://www.nngroup.com/articles/how-to-conductaheuristic-evaluation/. Diakses Pada 21-Juli-2021.

Krisnayani, P., Arthana, I Ketut R., Darmawiguna, I Gede M., (2016) Analisa Usability Pada Website UNDIKSHA Dengan Menggunakan Metode Heuristic Evaluation, Kumpulan Artikel Mahasiswa Pendidikan Teknik Informatika (KARMAPATI) Volume 5 Nomor 2.

Mulia Sulistiyono (2017) Evaluasi Heuristic Sistem Informasi Pelaporan Kerusakan Laboratorium Universitas Amikom Yogyakarta. Jurnal Ilmiah DASI Vol. 18 No. 1 Hlm. 37-43 ISSN: 1411-3201

Murdiaty, Angela, Chatrine Sylvia. (2019), dengan judul "Evaluasi Desain Antarmuka Portal Akademik Menggunakan Metode Heuristic Evaluation. JURNAL MEDIA INFORMATIKA BUDIDARMA, Vol 3, No 4, Oktober 2019 ISSN 2614-5278 (media cetak) ISSN 2548-8368 (media online) Hal 391-399 | DOI: 10.30865/mib.v3i4.1547.

Nielsen, J. Heuristics Evaluation. In Nielsen J. And Mack, R. L. (Eds.), (1994) Usablity Inspection Methods, Jhon Wiley \& Sons, New York, USA.

Nielsen, J. (2012). Usability 101: Introduction to usability [e-journal]. Tersedia di: http://www.nngroup.com/articles/usability-101-introduction-to-usability/ Diakses Pada 21-Juli-2021.

Rahmad Zapriant A. Dzazuly, Widhy Hayuhardhika N. Putra, Niken Hendrakusma Wardani (2019) dengan judul Evaluasi Usability dan Perbaikan Desain Antarmuka Pengguna Website Perpustakaan Kota Malang menggunakan Metode Evaluasi Heuristik. Jurnal Pengembangan Teknologi Informasi dan Ilmu Komputer e-ISSN: 2548-964X Vol. 3, No. 6, Juni 2019, hlm. 5772-5779 http://j-ptiik.ub.ac.id

http://www.bpjsketenagakerjaan.go.id Di Akses Pada 25-Oktober-2020. 